\title{
The Importance of the Prenatal Environment in Behavioral Genetics: Introduction to Special Issue
}

\author{
Valerie S. Knopik $^{1,2} \cdot$ Jenae M. Neiderhiser $^{3} \cdot$ Eco de Geus $^{4} \cdot$ Dorret Boomsma $^{4,5}$
}

Received: 24 March 2016/ Accepted: 30 March 2016/Published online: 16 April 2016

(C) Springer Science+Business Media New York 2016

\begin{abstract}
We introduce and discuss a special issue on prenatal factors in genetics research, that includes 14 papers ranging from studies on chorionicity, smoking during pregnancy, and more general prenatal risks to papers about theory, methods and measurement. There are two review papers, one focused on chorioncity and the second on pre- and perinatal ischemia-hypoxia, that help to frame the state of research in these areas with a focus on the relevance across multiple fields of study. Taken together, these papers clearly demonstrate the importance of considering prenatal environment influences on functioning in offspring across the lifespan while also underscoring the importance of using genetically informed designs as a means to clarify causality.
\end{abstract}

\section{Introduction}

Over the past three decades, there has been growing interest in the prenatal environment as a critical window of fetal development as well as an important factor in later child, adolescent, and adult outcomes. This has occurred

Valerie S. Knopik

Valerie_Knopik@Brown.edu

1 Division of Behavioral Genetics, Department of Psychiatry, Rhode Island Hospital, Providence, RI, USA

2 Department of Psychiatry and Human Behavior, Brown University, Providence, RI, USA

3 Department of Psychology, The Pennsylvania State University, University Park, PA, USA

4 VU University, Amsterdam, The Netherlands

5 EMGO Institute for Health and Care Research, Amsterdam, The Netherlands both in the popular news media (e.g., Paul 2010) and in the research domain; although reviews on this issue can be found as early as 1950 (Price 1950, 1978). Epidemiological studies have explored the links between adverse prenatal conditions and increased risk for diseases, health problems, and psychological outcomes later in life. Such studies have historically examined the Dutch Famine Birth Cohort, which consists of men and women born as term singletons in the western part of The Netherlands during or immediately following the Dutch Famine of 1944-1945 (de Rooij et al. 2010; Stein et al. 1972). The use of this particular cohort allowed the opportunity to examine the effects of one particular adverse exposure-starvation during pregnancy, even as a function of trimester-which was associated with outcomes such as schizophrenia, type 2 diabetes mellitus, cardiovascular disease, other metabolic disorders, and decreased cognitive function later in life (Argente et al. 2010; Barker and Clark 1997; de Rooij et al. 2010).

The theory of fetal programming, which was influenced by observations from the Dutch Famine Birth Cohort and initially proposed in the late 1980s, explains the influence of the in utero environment on the molecular character of development (Barker and Clark 1997; Hales and Barker 1992). David Barker coined the term fetal programming to describe his findings from epidemiological studies that linked health problems in middle-aged adults with low birthweight. The "Barker's hypothesis," also known as the "fetal origins" or the "thrifty phenotype hypothesis," suggested that maternal undernutrition during pregnancy affected later outcomes via fetal programming that permanently shaped the body's structure, function, and metabolism and contributed to later disease (Veenendaal et al. 2012; Wadhwa et al. 2009). Research aimed at better understanding the underlying mechanisms of fetal 
programming is ongoing and includes areas devoted to potential genetic/epigenetic mechanisms and adaptive responses of the fetus to a broader range of environmental cues, such as viruses, increased levels of stress during pregnancy and maternal substance use during pregnancy. To follow one specific example, maternal smoking during pregnancy certainly contributes to an adverse intrauterine environment. However, evidence that maternal cigarette smoking during pregnancy is correlated with other potential contributors to adverse prenatal environmental conditions can make causal attribution difficult (see Knopik 2009; D'Onofrio et al. 2013 for reviews). This is supported by recent work from our own groups and others suggesting that maternal smoking during pregnancy is correlated with many risk factors, such as obstetric complications and exposures (e.g., exposure to toxins like chemicals, pesticides) experienced in utero (Marceau et al. 2013), lower levels of maternal education (D'Onofrio et al. 2010), spousal/significant other substance dependence (Knopik et al. 2005, 2006), nicotine dependence (Agrawal et al. 2008), as well as maternal ADHD and other psychopathology (D'Onofrio et al. 2010; Huizink and Mulder 2006; Knopik 2009; Knopik et al. 2009), all of which may come with a host of additional influences on the intrauterine environment that also predict later offspring behavior.

We are therefore faced with the looming question of causality. Do adverse intrauterine conditions cause undesirable outcomes? Or is it the host of correlated factors, such as the genetic predisposition of the mother, the genetic predisposition of father through mechanisms of assortment, and thus genetic predisposition of the child, that leads to later behavioral and health outcomes? Further, the results of research in the prenatal domain are only as robust as the phenotypes (both prenatal environment and outcomes) that are assessed. While prospective study designs may be the gold standard, in situations where this is impossible, to what extent can we rely on retrospective reporting of prenatal variables? Are birth records or medical records accurate? The use of carefully designed studies using quality assessment of the prenatal environment in addition to behavioral genetic and molecular genetic designs can begin to resolve questions of causality (e.g., Katan 1986; Keavney 2004; D'Onofrio et al. 2016). Given the growing interest in this area, we felt a special issue of Behavior Genetics devoted to these topics was warranted.

\section{Contents of the special issue}

The breadth and depth of articles in this issue is notable. A variety of genetically-informed approaches are utilized to examine the importance of the prenatal environment resulting in a set of studies that may be more representative than any one study alone. These approaches include withinfamily (twin, discordant twin, sibling and cousin comparisons), adoption, propensity score analysis, polygenic risk scores, and the incorporation of additional observational data regarding mothers' behavior during pregnancy (i.e., partner report of maternal behavior) as well as additional indices of perinatal risk (e.g., partner smoking in addition to maternal smoking during pregnancy). These varied approaches investigate multiple facets of the prenatal environment, including chorionicity in twins, obstetric complications, prenatal substance exposure, and maternal stress during pregnancy, while also addressing issues of how best to assess the prenatal environment in geneticallyinformed approaches and beyond. Finally, and perhaps more striking, is the application of these various modeling approaches to test the importance of the prenatal environment on a variety of health and behavior outcomes that capture the developmental spectrum from infancy to adulthood. These include, but are not limited to gestational age, birthweight, internalizing and externalizing behaviors in toddlers and in preschoolers, cognitive ability in childhood/early adolescence, substance use initiation, and selfperceived health in adults.

There are five general themes of the papers in this special issue: chorionicity, theory and methods, measurement, maternal smoking during pregnancy, and maternal/ perinatal factors. Each of these themes is addressed by at least two papers, with a total of fourteen papers comprising this special issue. We believe that taken as a whole this work highlights the importance of both prenatal environment and genetic influences on understanding outcomes, and most critically, for considering both prenatal and genetic influences for a more complete and nuanced understanding of human development.

We open with two papers on chorionicity; whereas dizygotic twins always have two chorions, monozygotic twins can have two chorions or share one chorion. This is a topic that has received some recent attention from researchers as a challenge to the validity of twin designs, especially in regard to the equal environments assumption. In the Marceau et al. (2016a) review, the published literature examining chorionicity was summarized to clarify how often this has been considered in relation to heritability estimates and, further, whether chorionicity effects may systematically bias heritability estimates. The most consistent finding was that heritability for birth weight and early growth was underestimated when chorionicity was not taken into account. A second paper examined three different types of MZ twins: those who share one chorion and one amnion, those who share one chorion but have their own amnion, and those who share neither (van Beijsterveldt et al. 2016). For over 60 developmental 
phenotypes, some differences in MZ twin similarity were found as a function of these categories, but the overall effects of these differences were small and do not bias heritability estimates from twin studies.

Two papers on theory and methods take advantage of genetically informative designs in novel ways. Specifically, D'Onofrio et al. (2016) describes a strategy of using measured covariates within the sibling-comparison and other related designs to better specify the sources of covariation between perinatal exposures and later outcomes. The use of such strategies is critical for clarifying possible biological mechanisms, especially when multiple genetically informed approaches are combined with careful measurement. Loehlin (2016) provides an insightful concept paper that highlights the ability of adoption studies to estimate the effects of the prenatal and the postnatal environment when information from adoptive parents, birth mother, and birth father is available. The example correlations for IQ in the adopted child with adoptive mother, birth mother, and birth father clearly indicate that genetic and prenatal environmental influences have the largest effect on offspring IQ scores, although the postnatal environment also has a modest effect. Both of these papers remind us of the importance of collecting data from multiple family members and of the need to use a variety of strategies and designs to best understand how genes, prenatal environment, and postnatal environments may influence outcomes.

The papers by Knopik et al. (2016) and Neiderhiser et al. (2016) both address the value of self-report data for assessment of the prenatal environment. In both projects self-report data were collected retrospectively, but other strategies were also used to enhance both the accuracy of the self-report data and the detail of the information collected. Generally, Neiderhiser et al. found relatively high agreement between self-report and medical records' data with greater sensitivity for severity of commonly used substances in the self-report data. This study also reported that the combined effects of genetic, perinatal, and postnatal risks interact to influence internalizing and externalizing symptoms during early childhood. Knopik et al. (2016) focused on identifying the optimal method for assessing smoking during pregnancy (SDP) by comparing rates of agreement across maternal reports, paternal reports of maternal smoking behavior and birth records. These findings support the use of self-report data from mothers and fathers and found a causal association between SDP and birth weight, after controlling for genetic and familial confounds using a sibling comparison approach. Taken together, these two reports both highlight the importance of collecting data on the prenatal (and postnatal) environments and support the utility of using retrospective reports from mothers and fathers, increasing the feasibility of including data on the prenatal environment in large research studies.

The role of SDP on later offspring behavior was the focus of five papers in this special issue. This reflects, in part, the relatively high prevalence of SDP (about $15 \%$ in the United States), the straightforward assessment of SDP, and the fact that SDP has been found to relate to a variety of behavioral and health outcomes in children and in adults. The first of these papers (Marceau et al. 2016b) proposes a strategy for distinguishing between passive gene-environment correlation ( $r \mathrm{GE})$ and a cascading effect due to shared genes for smoking behavior and exposure that then result in environmental influences of SDP on child behavioral outcomes. This paper is the first one to combine a polygenic risk score approach with research into prenatal environmental exposures. While first results were nonsignificant by traditional standards, this conceptual framework provides a research strategy for considering these two possible pathways for the impact of SDP on offspring outcomes. In the second paper focused on SDP, data from the large Netherlands Twin Register were analyzed to examine SDP and internalizing and externalizing behaviors during early childhood. Dolan et al. (2016) incorporated paternal smoking into the model and also considered the possible beneficial effect of quitting smoking before pregnancy in mothers who were established smokers. Findings suggest that maternal SDP showed a greater effect than paternal smoking and that quitting smoking before pregnancy was linked with lower levels of externalizing behaviors in 3-year-old children, indicating a causal effect of SDP on externalizing problems during childhood. No such effect was observed for internalizing problems.

Estabrook et al. (2016) focused on examining how maternal SDP is linked with externalizing symptoms in preschool-aged children using a within-family design that assesses variation in smoking across multiple children in the same family. This report found unique effects of maternal SDP on disruptive externalizing behaviors after genetic and familial factors were accounted for. This report also found that measuring the variation in prenatal smoking patterns within and across pregnancies and families is critical for detecting direct effects of SDP on child outcomes. The two final SDP papers used a propensity scoring approach in the Missouri Adolescent Female Twin Study. Palmer et al. (2016) examined how the effects of maternal SDP on offspring externalizing behavior may differ if the mother smoked only during her first trimester as compared to smoking throughout her pregnancy. The findings indicated that there was a direct effect of maternal SDP on offspring externalizing behavior, but that this direct association varied in a way consistent with a dose-response effect and was confounded, in part, with familial factors. 
Finally, Bidwell et al. (2016) examined initial reactions to alcohol and cigarettes as a function of maternal SDP. Maternal SDP throughout the pregnancy was a unique risk factor for specific alcohol initiation reactions in the middle range of the risk distribution, but not in the lowest and highest risk quartiles. Taken together these five papers support a causal effect of SDP, with effect sizes depending on the phenotype studied. In all instances, the direct effects of maternal SDP were attenuated when familial confounds were included. Thus, they illustrate the importance of examining the effects of maternal SDP within the context of genetically informed designs. Studies that do not take familial confounds into account will likely overestimate the effects of maternal SDP.

The final three papers of this special issue address distinct perinatal factors that have been shown to be related to adverse outcomes in offspring throughout the lifespan. First, Sujan et al. (2016) examined maternal age at childbearing as a risk factor for shorter gestational age and lower fetal growth using two genetically informed designs (cousin and sibling comparisons) and data from two cohorts. This report found that only a shorter gestational age was associated with increased maternal age after controlling for shared familial factors. Mosing et al. (2016) used a co-twin control study to examine the longlasting effects of low birth weight on self-perceived health in early and later adulthood. This study is consistent with a growing literature linking early risk factors from prenatal to early childhood on adult and aging outcomes. Although lower birth weight was associated with poorer self-perceived health, the effect size was small and the co-twin control analyses suggested that shared familial factors may account for this association. Finally, Smith et al. (2016) provided a comprehensive review of the literature examining insufficient blood and oxygen supply-prenatal ischemia-hypoxia—in utero as a mechanism for producing neurodevelopmental risk for ADHD. Prenatal ischemia-hypoxia may initiate a common early etiological pathway to ADHD which, if identified early, may provide a strong early target for intervention. Smith et al. go on to propose a number of strategies to better identify when prenatal ischemia-hypoxia may have occurred during pregnancy and birth as well as a multi-omic approach that would allow the interplay among prenatal environmental risk, genomic, epigenomic, and transcriptomic factors to be clarified in the development of ADHD. An important suggestion contained in this future framework is that researchers interest in the prenatal environment as a critical window of fetal development should invest in collecting birth tissues as an important source of reconstructing the molecular biological events during pregnancy.

\section{Summary}

The overarching conclusions arising from this special issue are two-fold. First, an adverse prenatal environment can have detrimental effects on later behavioral and health outcomes. Second, the size of the effect of the prenatal environment is, in many cases, reduced when familial factors are taken into account. Correct effect-size estimation is vital for studies on the (cost)effectiveness of behavioral or other interventions during this first and critical phase of life. Thus, the importance of using genetically informed designs when examining the existence and extent of causal perinatal effects cannot be underestimated (e.g., De Moor et al. 2008; D'Onofrio et al. 2016; Eaves et al. 2014). One of the strengths of behavioral genetic designs is the ability to replicate using a variety of specific designs and related measures (Plomin et al. 2016). The studies described in this special issue encourage others to continue examining the role of the prenatal environment, to incorporate careful measurement (both of the prenatal environment but also of the offspring outcomes of interest) and to use theory-driven approaches in this effort. We would also encourage future studies to include careful measurement of the postnatal environment as one strategy for identifying specific factors that comprise "familial confounds" often indicated in this body of work.

Conflict of Interest Valerie S. Knopik, Jenae M. Neiderhiser, Eco de Geus, and Dorret I. Boomsma declare that they have no conflicts of interest.

\section{References}

Agrawal A, Knopik VS, Pergadia ML, Waldron M, Bucholz KK, Martin NG, Madden PA (2008) Correlates of cigarette smoking during pregnancy and its genetic and environmental overlap with nicotine dependence. Nicotine Tob Res 10(4):567-578. doi:10. 1080/14622200801978672

Argente J, Mehls O, Barrios V (2010) Growth and body composition in very young SGA children. Pediatr Nephrol 25(4):679-685. doi:10.1007/s00467-009-1432-2

Barker DJ, Clark PM (1997) Fetal undernutrition and disease in later life. Rev Reprod 2(2):105-112

Bidwell LC, Palmer RHC, Brick L, Heath AC, Madden PAF, Knopik VS (2016) A propensity scoring approach to characterizing the effects of maternal smoking during pregnancy on offspring's initial responses to cigarettes and alcohol. Behav Genet. doi:10. 1007/s10519-016-9791-5

D'Onofrio BM, Lahey BB, Turkheimer E, Lichtenstein P (2013) The critical need for family-based, quasi-experimental research in integrating genetic and social science research. Am J Public Health 103:S46-S55

De Moor MH, Boomsma DI, Stubbe JH, Willemsen G, de Geus EJ (2008) Testing causality in the association between regular exercise and symptoms of anxiety and depression. Arch Gen Psychiatry 65(8):897-905 
de Rooij SR, Wouters H, Yonker JE, Painter RC, Roseboom TJ (2010) Prenatal undernutrition and cognitive function in late adulthood. Proc Natl Acad Sci USA 107(39):16881-16886. doi:10.1073/pnas.1009459107

Dolan CV, Geels L, Vink JM, van Beijsterveldt CE, Neale MC, Bartels M, Boomsma DI (2016) Testing causal effects of maternal smoking during pregnancy on offspring's externalizing and internalizing behavior. Behav Genet. doi:10.1007/s10519-015-9738-2

D'Onofrio BM, Singh AL, Iliadou A, Lambe M, Hultman CM, Neiderhiser JM, Lichtenstein P (2010) A quasi-experimental study of maternal smoking during pregnancy and offspring academic achievement. Child Dev 81(1):80-100. doi:10.1111/j. 1467-8624.2009.01382.x

D’Onofrio BM, Class QA, Rickert ME, Sujan AC, Larsson H, KujaHalkola R, Sjölander A, Almqvist C, Lichtenstein P, Oberg AS (2016) Translational epidemiologic approaches to understanding the consequences of early-life exposures. Behav Genet. doi:10. 1007/s10519-015-9769-8

Eaves LJ, Pourcain BS, Smith GD, York TP, Evans DM (2014) Resolving the effects of maternal and offspring genotype on dyadic outcomes in genome wide complex trait analysis ("M-GCTA"). Behav Genet 44(5):445-455. doi:10.1007/s10519014-9666-6

Estabrook R, Massey SH, Clark CA, Burns JL, Mustanski BS, Cook EH, O’Brien TC, Makowski B, Espy KA, Wakschlag LS (2016) Separating family-level and direct exposure effects of smoking during pregnancy on offspring externalizing symptoms: bridging the behavior genetic and behavior teratologic divide. Behav Genet. doi:10.1007/s10519-015-9762-2

Hales CN, Barker DJ (1992) Type 2 (non-insulin-dependent) diabetes mellitus: the thrifty phenotype hypothesis. Diabetologia 35(7): 595-601

Huizink AC, Mulder EJ (2006) Maternal smoking, drinking or cannabis use during pregnancy and neurobehavioral and cognitive functioning in human offspring. Neurosci Biobehav Rev 30(1):24-41

Katan MB (1986) Apolipoprotein E isoforms, serum cholesterol, and cancer. Lancet 1:507-508

Keavney B (2004). Commentary: Katan's remarkable foresight: genes and causality 18 years on. Int J Epidemiol 33(1):11-14

Knopik VS (2009) Maternal smoking during pregnancy and child outcomes: real or spurious effect? Dev Neuropsychol 34(1): 1-36. doi:10.1080/87565640802564366

Knopik VS, Sparrow EP, Madden PA, Bucholz KK, Hudziak JJ, Reich W, Heath AC (2005) Contributions of parental alcoholism, prenatal substance exposure, and genetic transmission to child ADHD risk: a female twin study. Psychol Med 35(5):625-635

Knopik VS, Heath AC, Jacob T, Slutske WS, Bucholz KK, Madden PA, Martin NG (2006) Maternal alcohol use disorder and offspring ADHD: disentangling genetic and environmental effects using a children-of-twins design. Psychol Med 36(10):1461-1471. doi:10.1017/s0033291706007884

Knopik VS, Jacob T, Haber JR, Swenson LP, Howell DN (2009) Paternal alcoholism and offspring ADHD problems: a children of twins design. Twin Res Hum Genet 12(1):53-62. doi:10.1375/twin.12.1.53

Knopik VS, Marceau K, Palmer RH, Smith TF, Heath AC (2016) Maternal smoking during pregnancy and offspring birth weight: a genetically-informed approach comparing multiple raters. Behav Genet. doi:10.1007/s10519-015-9750-6

Loehlin JC (2016) What can an adoption study tell us about the effect of prenatal environment on a trait? Behav Genet. doi:10.1007/ s10519-015-9730-x

Marceau K, Hajal N, Leve LD, Reiss D, Shaw DS, Ganiban JM, Neiderhiser JM (2013) Measurement and associations of pregnancy risk factors with genetic influences, postnatal environmental influences, and toddler behavior. Int $\mathrm{J}$ Behav Dev 37(4):366-375. doi:10.1177/0165025413489378

Marceau K, McMaster MT, Smith TF, Daams JG, van Beijsterveldt CE, Boomsma DI, Knopik VS (2016a) The prenatal environment in twin studies: a review on chorionicity. Behav Genet. doi:10. 1007/s10519-016-9782-6

Marceau K, Palmer RH, Neiderhiser JM, Smith TF, McGeary JE, Knopik VS (2016b) Passive rGE or developmental geneenvironment cascade? An investigation of the role of xenobiotic metabolism genes in the association between smoke exposure during pregnancy and child birth weight. Behav Genet. doi:10. 1007/s10519-016-9778-2

Mosing MA, Cnattingius S, Gatz M, Neiderhiser JM, Pedersen NL (2016) Associations between fetal growth and self-perceived health throughout adulthood: a co-twin control study. Behav Genet. doi:10.1007/s10519-015-9776-9

Neiderhiser JM, Marceau K, de Araujo-Greecher M, Ganiban JM, Shaw DS, Reiss D, Leve LD (2016) Comparing medical records and self-report to measure pregnancy and delivery risk: estimating the roles of genetic risk, perinatal risk, and rearing environment on early childhood adjustment. Behav Genet. doi:10.1007/s10519-016-9788-0

Palmer RH, Bidwell LC, Heath AC, Brick LA, Madden PA, Knopik VS (2016) Effects of maternal smoking during pregnancy on offspring externalizing problems: contextual effects in a sample of female twins. Behav Genet. doi:10.1007/s10519-016-9779-1

Paul AM (2010) How the first nine months shape the rest of your life. Time Magazine, 22 Sept 2010

Plomin R, DeFries JC, Knopik VS, Neiderhiser JM (2016) Top 10 replicated findings from behavioral genetics. Perspect Psychol Sci 11(1):3-23

Price B (1950) Primary biases in twin studies; a review of prenatal and natal difference-producing factors in monozygotic pairs. Am J Hum Genet 2(4):293-352

Price B (1978) Bibliography on prenatal and natal influences in twins. Acta Genet Med Gemellol 27:97-113

Smith TF, Schmidt-Kastner R, McGeary JE, Kaczorowski JA, Knopik VS (2016) Pre- and perinatal ischemia-hypoxia, the ischemiahypoxia response pathway, and ADHD risk. Behav Genet. doi:10.1007/s10519-016-9784-4

Stein Z, Susser M, Saenger G, Marolla F (1972) Nutrition and mental performance. Science 178(62):708-713

Sujan AC, Rickert ME, Class QA, Coyne CA, Lichtenstein P, Almqvist C, Larsson $\mathrm{H}$, Sjölander A, Lahey BB, van Hulle C, Waldman I, Öberg AS, D'Onofrio BM (2016) A genetically informed study of the associations between maternal age at childbearing and adverse perinatal outcomes. Behav Genet. doi:10.1007/s10519-015-9748-0

van Beijsterveldt CE, Overbeek LI, Rozendaal L, McMaster MT, Glasner TJ, Bartels M, Vink JM, Martin NG, Dolan CV, Boomsma DI (2016) Chorionicity and heritability estimates from twin studies: the prenatal environment of twins and their resemblance across a large number of traits. Behav Genet. doi:10.1007/s10519-015-9745-3

Veenendaal MV, Costello PM, Lillycrop KA, de Rooij SR, van der Post JA, Bossuyt PM, Roseboom TJ (2012) Prenatal famine exposure, health in later life and promoter methylation of four candidate genes. J Dev Orig Health Dis 3(6):450-457. doi:10. 1017/s2040174412000396

Wadhwa PD, Buss C, Entringer S, Swanson JM (2009) Developmental origins of health and disease: brief history of the approach and current focus on epigenetic mechanisms. Semin Reprod Med 27(5):358-368. doi:10.1055/s-0029-1237424 